\title{
Perinatal outcome of term pregnancies with borderline amniotic fluid index: a prospective case control study
}

\author{
Devika V. Desai*, Nigamananda Mishra, Gayatri V. Savani
}

Department of Obstetrics and Gynecology, Bhabha Atomic Research Centre and Hospital, Mumbai, Maharashtra, India

Received: 26 February 2020

Accepted: 30 March 2020

*Correspondence:

Dr. Devika V. Desai,

E-mail: devikadesai1090@gmail.com

Copyright: () the author(s), publisher and licensee Medip Academy. This is an open-access article distributed under the terms of the Creative Commons Attribution Non-Commercial License, which permits unrestricted non-commercial use, distribution, and reproduction in any medium, provided the original work is properly cited.

\section{ABSTRACT}

Background: It has been since antiquity that the importance of amniotic fluid and fetal growth with perinatal outcome is being documented. But the lacunae lies in studying the relationship between borderline amniotic fluid and perinatal outcome. The following study was undertaken to provide recent data that would help predict perinatal outcome in borderline AFI pregnancies.

Methods: About 144 patients were considered in the study OPD/IPD patients in obstetrics and gynecology department in Bhabha Atomic Research Centre and Hospital, with about 72 cases with borderline amniotic fluid index $(5-8 \mathrm{~cm})$ and controls with amniotic fluid index $\geq 9-25 \mathrm{~cm}$. Patients were selected and subjected to history taking, examination, ultrasound test with doppler studies and perinatal outcome documented over a period of one year.

Results: The incidence of borderline AFI in my study was $16 \% .58 \%$ were primigravidas. Meconium stained liquor was found in $18 \%$ cases compared to $7 \%$ controls. Low birth weight was found in $12.5 \%$ cases and $2.7 \%$ in controls. On applying statistical test analysis chi square test, it was found that borderline amniotic fluid index in relation to presence of meconium stained amniotic fluid and low birth weight, $\mathrm{p}$ value was found to be statistically significant $(<0.05)$.

Conclusions: Borderline amniotic fluid and perinatal outcome had significant relationship in terms of meconium stained liquor and birth weight while rest had no significance. Thus, borderline amniotic fluid patients require vigilant fetal surveillance.

Keywords: Borderline amniotic fluid, Doppler studies, Low birth weight, Meconium stained liquor, Perinatal outcome

\section{INTRODUCTION}

Amniotic fluid index is a marker for antenatal and intrapartum fetal monitoring in high risk pregnancies, and helps in early recognition of fetal compromise. ${ }^{1}$ Phelan et al proposed the concept of amniotic fluid index, range being $5-25 \mathrm{~cm}$, measured by adding single deep quadrant in all four quadrants. ${ }^{2}$ Borderline AFI is defined as between $5-8 \mathrm{~cm} .^{3}$ There have been studies since antiquity suggesting a strong relationship between oligohydramnios and polyhydramnios and documented in literature. Borderline amniotic fluid index is the least studied in terms of antenatal fetal surveillance, doppler indices and perinatal outcome. Hence, the following study.

\section{METHODS}

The study was undertaken post appropriate scientific and ethical committee approval. Patients OPD/IPD coming to an urban hospital $>37$ weeks of gestation were selected post inclusion and exclusion criteria and subjected to 
history taking, examination and ultrasound study including doppler indices. Sample size calculated according to prevalence of $5 \%$ was $72 .{ }^{4}$ Total 72 cases with patients who are term with borderline amniotic fluid, singleton pregnancy were selected while preterm gestation, premature rupture of membranes, multiple pregnancies, anomalous fetus and previous caesarean were excluded. Case record forms were filled post consent of patients. Perinatal outcome was studied in terms of mode of delivery, type of delivery, fetal birth weight, liquor volume, Apgar score, need for NICU admission and also any antenatal doppler changes present was documented.

\section{Statistical analysis}

Statistical analysis was done using software SPSS version 20.0. Demographic factors and clinical characteristics were summarized as counts (percentages) for categorical variables like age, parity, amniotic fluid index, type and mode of delivery, fetal birth weight, doppler changes and need for resuscitation and NICU admission. Chi square test was used to find any significant association between variables. A $\mathrm{p}$ value of less than 0.05 was considered significant.

\section{RESULTS}

Study was undertaken to compare perinatal outcomes between patients with borderline amniotic fluid index with normal amniotic fluid index. Parameters studied were doppler changes in ultrasound, type of delivery, mode of delivery, fetal birth weight, apgar score and need for NICU admission or resuscitation. Out of total 72 cases majority were among age group of 26-30 yearsaround $52 \%$. Among total 72 controls majority were among age group of 20-25 years- around 37.5\%.\%. As per Table 1, majority of patients among borderline group were from AFI - $8(51 \%)$ while majority of patients among control group were from AFI - 12-14 (45\%).

Table 1: Distribution of AFI among cases and controls.

\begin{tabular}{|ll|}
\hline AFI & Cases \\
\hline 5 & $7(9.7 \%)$ \\
\hline 6 & $9(12.5 \%)$ \\
\hline 7 & $19(26.4 \%)$ \\
\hline 8 & $37(51.4 \%)$ \\
\hline Grand total & 72 \\
\hline AFI & Controls \\
\hline $9-11$ & $21(29.1 \%)$ \\
\hline $12-14$ & $33(45.9 \%)$ \\
\hline $15-17$ & $13(18 \%)$ \\
\hline$>18$ & $5(7.0 \%)$ \\
\hline Grand total & 72 \\
\hline
\end{tabular}

Ultrasound done antenatally at term $>37$ weeks with doppler study stated-normal study in $87.5 \%$, raised S/D ratio in $9.7 \%$ followed by early prediastolic notching in bilateral uterine arteries seen in $1.4 \%$ and absent diastolic flow seen in $1.4 \%$ among borderline amniotic fluid index group. Around $45 \%$ among them, had to undergo caesarean section.

Similarly, among controls doppler studies stated-normal study in $93.1 \%$, raised S/D ratio in $5.6 \%$ followed by raised S/D with decreased PI values $1.4 \%$ among controls. Around $25 \%$ underwent caesarean section. Rest of the group had normal doppler studies.

Table 2: Results of various parameters among and cases and controls.

\begin{tabular}{|c|c|c|c|c|}
\hline Parameters & Cases (no.) $\mathbf{N}=72$ & Percentage & Controls (no.) $\mathbf{N}=72$ & Percentage \\
\hline \multicolumn{5}{|l|}{ Parity } \\
\hline Primigravida & 42 & $58.3 \%$ & 41 & $56.9 \%$ \\
\hline Multigravida & 30 & $41.7 \%$ & 31 & $43.1 \%$ \\
\hline \multicolumn{5}{|l|}{ Type of delivery } \\
\hline Induction of labor & 34 & $47.2 \%$ & 28 & $38.8 \%$ \\
\hline Spontaneous & 38 & $52.8 \%$ & 44 & $61.1 \%$ \\
\hline \multicolumn{5}{|l|}{ Mode of delivery } \\
\hline Caesarean section & 29 & $38 \%$ & 20 & $27 \%$ \\
\hline Normal vaginal delivery & 43 & $62 \%$ & 52 & $73 \%$ \\
\hline Meconium stained liquor & 13 & $18.1 \%$ & 5 & $7 \%$ \\
\hline Apgar score $<7$ & 3 & $4.2 \%$ & 2 & $2.8 \%$ \\
\hline Low birth weight & 9 & $12.5 \%$ & 2 & $2.7 \%$ \\
\hline
\end{tabular}

According to Table 2, it is evident that primigravida constituted the majority among both cases and controls. Cases underwent induction of labor more than controls by a small margin, while rest came in spontaneous labor. It is clear that cases underwent caesarean section of around 38 percent as compared to controls of around $27 \%$. Meconium stained liquor and low birth incidence was observed to be largely high as compared to controls. 
Majority underwent LSCS in view of non-progress of labor $(35.7 \%)$ with others being failed induction $(17.9 \%)$ and meconium stained liquor in $14.3 \%$ in cases while among controls around $45 \%$ underwent LSCS in view of non-progress of labor with others being fetal distress $25 \%$, cephalopelvic disproportion in labor $10 \%$ and meconium stained liquor $5 \%$ among controls.

The following Table 3 depicts the rate of NICU admissions among cases and controls and respective indications. On applying statistical test analysis chi square test, as depicted in Table 4 it was found that borderline amniotic fluid index in relation to presence of meconium stained amniotic fluid and low birth weight, $p$ value was found to be statistically significant. Chi square test when applied for rest it was found to have no statistically significant relationship.

Table 3: NICU admission among cases and controls.

\begin{tabular}{|ll|l|}
\hline NICU admission & Cases (no.) & Controls (no.) \\
\hline Hypoglycaemia & 1 & - \\
\hline Perinatal asphyxia & 2 & - \\
\hline LBW & 1 & - \\
\hline RDS & 1 & - \\
\hline Tachypnoea & - & 1 \\
\hline Early onset sepsis & - & 1 \\
\hline Total & 5 & 2 \\
\hline
\end{tabular}

Table 4: Test of significance applied.

\begin{tabular}{|c|c|c|c|c|c|c|}
\hline Sr. No. & Parameter & & Cases & Controls & p value & Significance \\
\hline \multirow{2}{*}{1} & \multirow{2}{*}{ Type of delivery } & LSCS & 29 & 20 & 0.1134 & No \\
\hline & & Vaginal & 43 & 52 & & \\
\hline \multirow{2}{*}{2} & \multirow{2}{*}{ Doppler changes } & Present & 9 & 5 & 0.2605 & No \\
\hline & & Absent & 63 & 67 & & \\
\hline \multirow{2}{*}{3} & \multirow{2}{*}{ Color of liqour } & Clear & 59 & 67 & 0.04382 & Yes \\
\hline & & Meconium stained & 13 & 5 & & \\
\hline \multirow{2}{*}{4} & \multirow{2}{*}{ Birth weight } & LBW & 9 & 2 & 0.028 & Yes \\
\hline & & Normal & 63 & 70 & & \\
\hline \multirow{2}{*}{5} & \multirow{2}{*}{ Apgar score } & $<7$ & 3 & 2 & 0.6489 & No \\
\hline & & $>7$ & 69 & 70 & & \\
\hline \multirow{2}{*}{6} & \multirow{2}{*}{ NICU admission } & Yes & 5 & 3 & 0.46685 & No \\
\hline & & No & 67 & 69 & & \\
\hline
\end{tabular}

\section{DISCUSSION}

A prospective case control study was done over a span of 1 year consisting of women of any parity at term i.e. $>37$ weeks with singleton pregnancy in unscarred uterus. A total of 144 pregnancies were considered out of which 72 were cases with borderline amniotic fluid with 72 controls having normal amniotic fluid index.

Ultrasound doppler parameters and perinatal outcomes were compared. Ultrasound parameters was done on OPD/IPD basis after 37 weeks of gestation along with doppler indices and compared the perinatal outcomes in terms of type of delivery, mode of delivery, fetal birth weight, Apgar score, need of intensive care unit management and resuscitation.

\section{Age group}

Our study included maximum patients between age group of 26-30 years. Ray et al had 73\% among age group 2029 years, whereas Tajinder et al had age group of 21-25 years as maximum number around $66 \%$, and Mahapatrol et al had $85 \%$ belonging to age group 20-29 years $^{.5-7}$

\section{Parity}

This study included primigravida's as maximum patients in both cases and controls. Similarly, Mahapatrol et al had primigravida's as majority. ${ }^{7}$ Jayathi Nath et al on the contrary had multigravidas as most common group around $64 \% .^{8}$

\section{Borderline amniotic fluid and its incidence}

In this study, we have considered borderline AFI as 5-8 $\mathrm{cm}$. However, Baron et al and Kwon et al also defined borderline oligohydramnios as amniotic fluid index of 5.1-8 cm whereas, Gumus et al have described borderline as AFI of $5.1 \mathrm{~cm}$ to $10 \mathrm{~cm}^{4,9,10}$ Magann EF et al conducted a metanalysis in the year 2011 and stated the incidence of borderline oligohydramnios (AFI 5.1-8 cm) as $6 \%$ to $44 \%$ with overall incidence being $12 \% .{ }^{11}$ In this study, over a duration of one year incidence of borderline amniotic fluid was found to be $16 \%$. Literature has stated that with advancing gestational age patients with borderline amniotic fluid index around $16 \%$ will have oligohydramnios. ${ }^{12}$ The morbidities associated with oligohydramnios has already been known to us. 


\section{Doppler changes}

There was an increased incidence by five fold in adverse perinatal outcome in patients with associated doppler changes in borderline amniotic fluid index patients in study by Kwon et al. ${ }^{4}$ Gaikwad et al found a rate of doppler changes in borderline AFI group as $15 \% .{ }^{13}$ Doppler indices studies done suggest that MCA/UA PI indexes a very sensitive and specific index for predicting fetal outcome. Decreased diastolic flow or reversal of ' $a$ ' wave flow has poorer outcome. ${ }^{14}$

\section{Type of delivery}

Jamal et al had found the incidence of caesarean section in borderline amniotic fluid index group around $26 \%$ more than the control group of normal amniotic fluid around $11 \%$ whereas in this study rate was $38 \%$ in case group with around $27 \%$ in control group. ${ }^{15}$ Patel et al reported the rate of caesarean section to be around $40 \%$ and Blaras et al as $44 \%$ in women with borderline oligohydramnios which was higher as compared to this study. ${ }^{16,17}$ In this study, the rate of caesarean section done for fetal distress in borderline amniotic fluid group was $4 \%$ as compared to $30 \%$ in control group. On the contrary, it was around 58\% in study by Patel et al, Ulker et al reported that the rate of caesarean section for fetal distress as $44 \%$ in women with borderline amniotic fluid and it was significantly higher than among women with normal liquor volume. ${ }^{16,18}$ Similarly, Kwon et al, also found that caesarean delivery for fetal distress was more common in borderline AFI group. ${ }^{4}$ Similarly, Mahapatrol et al observed an incidence of $29 \%$ LSCS rate, $2 \%$ instrumental vaginal delivery and 665 vaginal delivery. ${ }^{7}$

\section{Meconium stained liquor}

Meconium stained liquor is a known complication in oligohydramnios and in itself has morbidities in perinatal period. In this study, there was increased incidence of meconium stained liquor around $18 \%$ as compared to control group 5\%. Studies by Baron et al and Kwon observed no any significant difference in the incidence of meconium staining of liquor between women with borderline oligohydramnios and women with normal amniotic fluid volume. ${ }^{4,9}$ Giri et al, conducted a similar case control study for a duration of one year considering singleton term pregnancies around 165 with borderline AFI and compared the perinatal outcomes with normal AFI. It was found that there was increase in the incidence of caesarean sections around 33\%, meconium stained amniotic fluid, low Apgar scores, increased incidence of NICU admission but no significant incidence of intrauterine growth restriction. It was thus concluded that, borderline amniotic fluid index was associated with increased incidence of adverse perinatal outcomes which would require good antenatal fetal monitoring. They observed Apgar score of $<7$ at 5 minutes of life in $8 \%$ and rate of NICU admission as $18 \%$. Borderline AFI group with low birth weight was around $12 \%$ in this study. Similarly, Giri et al reported an incidence of $14 \% .{ }^{19}$

Table 5: Comparison of different studies.

\begin{tabular}{|llllll|}
\hline Parameters & Gaikwad et al $^{13}$ & Wood et a $^{\mathbf{2 6}}$ & Giri et al $^{19}$ & Ray et al $^{5}$ & Present study $^{\mathbf{1 3}}$ \\
\hline LSCS & $19 \%$ & $53 \%$ & $33 \%$ & $50 \%$ & $38 \%$ \\
\hline MSL & $25 \%$ & $16 \%$ & $31 \%$ & $76 \%$ & $18 \%$ \\
\hline Apgar $<7$ & $5.8 \%$ & $5 \%$ & $8 \%$ & $3.7 \%$ & $4.2 \%$ \\
\hline LBW & $64 \%$ & - & $12 \%$ & $50 \%$ & $12.5 \%$ \\
\hline NICU admission & $10 \%$ & $20 \%$ & $18 \%$ & - & $6.9 \%$ \\
\hline
\end{tabular}

\section{Perinatal outcome}

In this study, neonates with an Apgar score less than 7 at 5 minutes of life were significantly higher among women with borderline oligohydramnios (4\%) as compared to women with normal liquor volume $(1 \%)$. The rate of NICU admission was also significantly higher among women with borderline oligohydramnios (7\%) as compared to women with normal liquor volume (2.7\%). Similar to this study, Kwon et al, also observed a greater risk of neonates with an Apgar score less than 7 at 5 minutes of life and more NICU admission among women with borderline AFI. ${ }^{4}$ Banks et al, evaluated the perinatal outcome (intrapartum fetal distress, 5 minutes Apgar score $<7$ and meconium stained liquor) in women with borderline AFI and found that there was an increase in the incidence of adverse perinatal outcomes. 20Similarly,
Gumus et al also observed significantly increased incidence of NICU admissions in women with borderline AFI. ${ }^{10}$ Hashimoto et al stated that Apgar score $<7$ at 5 minutes of birth did not differ between two groups and there was increased NICU admission around $20.2 \%$ in the borderline AFI group. ${ }^{21}$ Ghike et al, observed the incidence of NICU admission as $19.05 \% .{ }^{22}$ Asgharnia et al, reported the incidence of NICU admission as $14.9 \%$ and Apgar score $<7$ at 5 minutes of birth as $20.2 \%$ in women with borderline oligohydramnios and both values were significantly higher than that seen in women with normal liquor volume. ${ }^{23}$ Similarly, Jamal et al reported that though there was a higher incidence of meconium stained liquor in women with borderline AFI and there was no significant difference in 5 minutes Apgar score, birth weight and NICU admission. ${ }^{24}$ In contrast, study done by Yaqoob et al, adverse perinatal outcomes were 
not found to be associated with borderline perinatal outcome. ${ }^{25}$ The Table 5 describes the comparison between variables analyzed in various studies and the present study. As is evident, NICU admissions are least in the present study while LSCS rate and Apgar scoring is almost similar. Meconium stained liquor and low birth weight are also on lower side.

Wood et al studied the relationship of borderline amniotic fluid with fetal intrapartum tolerance of labor, antenatal surveillance and outcome. He concluded that there is no significant difference in the parameters. Borderline amniotic fluid patients tend to undergo frequent antenatal surveillance offering no added benefit in the management. There was also increased presence of associated IUGR in these patients. ${ }^{26}$ Amniyos et al studied three groups of AFI $-\leq 3 \mathrm{~cm}, 5-\leq 8 \mathrm{~cm}$ and $8-$ $\leq 24 \mathrm{~cm}$ and compared the antenatal fetal parameters, intrapartum labor details and perinatal outcome. It was stated that with increasing gestational age, there was decrease in amniotic fluid volume with increase in abnormal fetal heart tracings, fetal distress. But there was no relation with cervical findings. ${ }^{27}$ Intrauterine growth restriction is well associated with adverse perinatal outcomes, and increased surveillance in its presence is both warranted and indicated antenatally and intrapartum. ${ }^{28}$

Every case needs to be individualized with respect to timing and route of delivery after appropriate discussion with the patient and relatives. Also providing good neonatal intensive care facilities helps optimize the perinatal outcome. ${ }^{5}$

In an era of cost effectiveness, it would seem reasonable to question the utility of increased surveillance for these pregnancies in case other co morbidities are not present. Multiple studies have reported an increased incidence of growth restriction or suboptimal growth in the setting of a borderline amniotic fluid index..$^{29-33}$

There could not be any specific perinatal care or other protocols for these patients and that could be because of different reasons such as the variations in the study designs, the likelihood of a borderline index varied from $6-44 \%$ and $25-35 \%$ and the absence of specific statistics to determine the thresholds of adverse outcomes, and therefore, more research will be required to find out the effect of AFI on adverse pregnancy outcome. ${ }^{34-36}$

Thus, study have seen a beautiful comparison and discussion of various studies and results along with graphical and tabular representation for better understanding.

\section{ACKNOWLEDGMENTS}

Authors would like to thank Dr. Santoshi Prabhu and Dr Vaishali Jadhav for their encouragement and support.
Funding: No funding sources

Conflict of interest: None declared

Ethical approval: The study was approved by the Institutional Ethics Committee

\section{REFERENCES}

1. Vermillion Stephen T, Kooba Austin M, Soper David E. Amniotic fluid index values after preterm premature rupture of the membranes and subsequent perinatal infection. Am J Obstet Gynecol. 2000;183:271-5.

2. Cunningham F, Leveno K, Bloom S, Spong CY, Dashe J. Amnionic fluid In Williams Obstetrics, $24^{\text {th }}$ edition, McGraw-Hill Education; 2014:231-233.

3. Underwood MA, Gilbert WM, Sherman MP. Amniotic fluid: not just fetal urine anymore. J Perinatol. 2005;25(5):341-8.

4. Kwon JY, Kwon HS, Kim YH, Park YW. Abnormal Doppler velocimetry is related to adverse perinatal outcome for borderline amniotic fluid index during third trimester. J Obstet Gynaecol Res. 2006;32(6):545-9.

5. Ray P, Mouli C, Bulusu R, Konar C, Resident J. A prospective study on the feto-maternal outcome in cases of borderline amniotic fluid index at term in a rural hospital. Indian $\mathrm{J}$ Obstet Gynecol Res. 2017;4(1):89.

6. Kaur T, Sood R. Feto maternal outcome in pregnancies with abnormal AFI. IOSR J Dent Med Sci. 2016;15:71-5.

7. Mahapatrol AK, Jena SK, Ghose S. Pregnancy outcome following induction of labour in oligohydramnios and borderline liquor at term: A comparative study. J Evol Med Dent Sci. 2013;52:10289-94.

8. Nath J, Jain M, Najam R. A Clinical study on oligohydramnios in the third trimester of pregnancy with special emphasis on the perinatal outcome. J Evol Med Dent Sci. 2013;39:7386-91.

9. Baron C, Morgan MA, Garite TJ. The impact of amniotic perinatal outcomes. Am J Obstet Gynecol. 1995;173:167-74.

10. Gumus II, Koktener A, Turhan NO. Perinatal outcome of pregnancies with borderline amniotic fluid index. Arch Gynecol Obstet. 2007;276:17-9.

11. Magann EF, Chauhan SP, Hitt WC, Dubil EA, Morrison JC. Borderline or marginal amniotic fluid index and peripartum outcomes: a review of the literature. J Ultrasound Med. 2011;30:523-8.

12. Wing DA, Fishman A, Gonzalez C, Paul RH. How frequently should amniotic fluid index be performed during the course of antepartum testing? Am J Obstet Gynecol. 1996;174:33-6.

13. Gaikwad P, Oswal M, Gandhewar M, Bhatiyani B. Perinatal outcome in oligohydramnios and borderline amniotic fluid index: a comparative study. Int $\mathbf{J}$ Reprod Contracept Obstet Gynecol. 2016;5(6):19648 . 
14. Mishra D, Sakhi P, Saraf A, Gupta A, Soni K, Dhruw S. Role of obstetric Doppler in prediction of adverse perinatal outcome in intrauterine growth retardation and pregnancy induced hypertension. artery. Sch J Appl Med Sci. 1960;28:46.

15. Jamal A, Abbasi S, Mesdaghima S. Borderline amniotic fluid index and adverse perinatal outcome. Ultrasound Obstet Gynecol. 2008;32:391-3.

16. Patel RR, Rathod HM, Punata PS, Rathod H. Perinatal outcome in women with oligohydramnios during 3rd trimester of pregnancy at Guru Gobind Singh Hospital - Jamnagar, Gujarat. Int J Rep Med. 2013;2:20-3.

17. Blaras K, Theodora M, Papantoniou N, Syndos M, Mesogitis S, Antsaklis A. Borderline oligohydramnios in singleton pregnancies with intact fetal membranes in the third trimester:Obstetric management and perinatal outcome. Arch Dis Child Fetal Neonatal. 2010;95(S1):29.

18. Ulker K, Ozdemir IA. The relation of intrapartum amniotic fluid index to perinatal outcomes. Kafkas J Med Sci. 2011;1:1-7.

19. Giri A, Srivastav VR, Tuladhar AS, Sharma B. Perinatal outcome of term pregnancies with borderline amniotic fluid index at Nepal Medical College and Teaching Hospital. Nepal Med Coll J. 2015;17(12):63-6.

20. Banks EH, Miller DA. Perinatal risks associated with borderline amniotic fluid index. Am J Obstet Gynecol. 1999;180:1461-3.

21. Hashimoto K, Kasdaghi T, Sharoky C. Perinatal outcome of mildly decreased AFI in third trimester. Ultrasound Obstet Gynecol. 2011;38(S1):53.

22. Ghike S. Reddy G, Ghike NW. Increasing severity of oligohydramnios: A risk factor for outcome. J South Asian Feder Obst Gynae. 2013;5:8-10.

23. Asgharnia M, Faraji R, Salamat F, Ashrafkhani B, Dalil Heirati SF, Naimian S. Perinatal outcomes of pregnancies with borderline versus normal amniotic fluid index. Iran J Reprod Med. 2013;11(9):705-10.

24. Jamal A, Kazemi M, Marsoosi V, Eslamian L. Adverse perinatal outcomes in borderline amniotic fluid index. Int J Reprod Biomed (Yazd, Iran). 2016;14(11):705-8.

25. Yaqoob S, Iqbal R. Relation between borderline amniotic fluid index and perinatal outcome. Pak J Med Health Sci. 2009;2:361-4.
26. Wood SL, Newton JM, Wang L, Lesser K. Borderline amniotic fluid index and its relation to fetal intolerance of labor. J Ultrasound Med. 2014;33(4):705-11.

27. Yazsi A. The relation of intrapartum amniotic fluid index to perinatal outcomes. Kafkas J Med Sci. 2011;1(1):1-7.

28. Minior VK, Divon MY. Fetal growth restriction at term: myth or reality? Obstet Gynecol. 1998;92:5760.

29. Pallotto EK, Kilbride HW. Perinatal outcome and later implications of intrauterine growth restriction. Clin Obstet Gynecol. 2006;49:257-69.

30. Garite TJ, Clark R, Thorp JA. Intrauterine growth restriction increases morbidity and mortality among premature neonates. Am J Obstet Gynecol. 2004;191:481-7.

31. McIntire DD, Bloom SL, Casey BM, Leveno KJ. Birth weight in relation to morbidity and mortality among newborn infants. $\mathrm{N}$ Engl J Med. 1999;340:1234-8.

32. Jones RA, Robertson NR. Problems of the small-fordates baby. Clin Obstet Gynecol. 1984;11:499-524.

33. Alkalay AL, Graham JM, Pomerance JJ. Evaluation of neonates born with intrauterine growth retardation: review and practice guidelines. J Perinatol. 1998; 18:142-51.

34. Manslow AS, Sweeny AL. Elective induction of labor as a risk factor for cesarean delivery among low-risk women at term. Obstet Gynecol. 2000;95:917-22.

35. Cammu H, Martens G, Ruyssinck G, Amy JJ. Outcome after elective labor induction in nulliparous women: a matched cohort study. Am J Obstet Gynecol. 2002; 186:240-4.

36. Ehrenthal SB, Jiang X, Strobino DM. Labor induction and the risk of a cesarean delivery among nulliparous women. Obstet Gynecol. 2010;116:3542.

Cite this article as: Desai DV, Mishra N, Savani GV. Perinatal outcome of term pregnancies with borderline amniotic fluid index: a prospective case control study. Int J Reprod Contracept Obstet Gynecol 2020;9:2047-52. 